To cite: Sarri G, Guo Y, Ineanacho I, et al. Moderately severe and severe acute pancreatitis : a systematic review of the outcomes in the USA and European Union-5. BMJ Open Gastro 2019;6:e000248. doi:10.1136/ bmjgast-2018-000248

Received 24 September 2018 Revised 13 December 2018 Accepted 24 December 2018
Check for updates

(C) Author(s) (or their employer(s)) 2019. Re-use permitted under CC BY-NC. No commercial re-use. See rights and permissions. Published by BMJ.

${ }^{1}$ Evidence Synthesis, Modeling \& Communication, Evidera, London, UK

${ }^{2}$ Global Outcomes Research, Takeda, London, UK

Correspondence to Dr Grammati Sarri;

Grammati.Sarri@evidera.com

\title{
Moderately severe and severe acute pancreatitis : a systematic review of the outcomes in the USA and European Union-5
}

\author{
Grammati Sarri, ${ }^{1}$ Yelan Guo, ${ }^{1}$ Ike Iheanacho, ${ }^{1}$ Jorge Puelles ${ }^{2}$
}

\begin{abstract}
Background and objectives The global incidence of hospitalisation due to acute pancreatitis (AP) has been rising in the recent decades. In the USA alone, there was a $13.2 \%$ increase between 2009 and 2012 compared with 2002-2005. There remains a lack of approved treatments to prevent disease progression, leaving many liable to developing complications that include multisystem organ failure (OF) and death. This therapeutic deficit raises questions about the scale of the current burden of illness (BOI) associated with severe forms of AP. The aim of the systematic literature review (SLR) was to assess clinical, humanistic, and economic outcomes associated with moderately severe AP (MSAP) and severe AP (SAP) in the USA and the European Union-5 (EU-5).
\end{abstract}

Methods Systematic searches were conducted in MEDLINE and Embase to identify studies published in English (between 2007 and 2017) that reported on the BOI of MSAP and/or SAP. Manual searches of 'grey' literature sources were also conducted.

Results The SLR identified 19 studies which indicated that $15 \%-20 \%$ of patients with AP progress to more severe forms of the disease, up to $10.5 \%$ of those with SAP require surgery for complications, and up to $40 \%$ die during hospitalisation. By contrast, there appears to be a lack of data on the extent to which SAP affects patients' quality of life.

Conclusion The available evidence clearly demonstrates that the current management for MSAP and SAP in the USA and EU-5 does not adequately meet patients' needs. Early identification and intervention for AP is crucial, given the evidence of high rates of morbidity and an associated economic burden that is considerable. Since many patients with the condition present to hospitals at a point when multisystem OF or death is highly likely, there is a particularly urgent need for effective treatment options to prevent disease progression.

\section{INTRODUCTION}

Acute pancreatitis (AP) involves acute inflammation of the pancreas and, sometimes, adjacent tissues. The occurrence of the condition has been increasing during the last 40 years, with incidence rates ranging from 20 to 80 per 100000 per annum and varying across countries. ${ }^{1}$ The proportion of Japan's population, for example, diagnosed in 2011 was estimated at 49.4 per 100000 , representing a 1.8-fold increase over the previous decade. ${ }^{2}$ A lower incidence estimate of AP hospital admissions has been reported in Europe. In Scotland, the incidence of AP hospital admissions was estimated at 33.1 per 100000 per year between 2009 and 2012. ${ }^{3}$ This, coupled with the rising global epidemiological burden of AP, helps to account for why the condition is a major consumer of healthcare resources and a significant driver of costs. AP accounted for 275000 hospital admissions and US\$2.6 billion in direct treatment costs in 2009 in the USA, where it is one of the leading gastrointestinal diseases. ${ }^{4}$

AP can rapidly progress into moderately severe AP (MSAP) or severe AP (SAP), ${ }^{5}$ and there is a lack of standard care of treatment for $\mathrm{AP}$ or $\mathrm{SAP}^{6}{ }^{6}$ Therefore, early clinical recognition of AP is crucial to managing disease progression-evidence shows that after the initial 48-72 hours, the progression of disease may be fully established, leading to multisystem organ failure (OF). Historically, however, inconsistencies in defining and categorising the severity of AP have presented a challenge in this regard and have complicated the delivery of appropriate care to patients with this potentially life-threatening condition. Against this background, the revised Atlanta classification (RAC) of AP was proposed in $2012^{5}$ to address confusion and related variation in classifying AP severity. The RAC defined and classified populations into the following three groups, with persistent OF being the main determinant of severity: mild AP (when no OF or local or systemic complications are present); MSAP (when OF is present and resolves within 48 hours and/ or local or systemic complications are present 
but without persistent OF) and SAP (when OF persists over 48 hours). This classification considers a biphasic natural course of AP, specifically, an early phase in which the presence or absence of persistent OF is determined, and a late phase in which local or systemic complications are investigated.

While the RAC has facilitated recognition of AP and early prediction of its progression to severe forms of the disease, there remain key questions about how patients with, or at risk of, SAP are best managed. Current traditional treatment for SAP, however, has been primarily conservative with more active management of disease progression being limited by the lack of globally recognised treatments. Protease inhibitors, such as gabexate mesilate, nafamostat mesilate and ulinastatin (UTI), have been recommended as treatments for AP and/or SAP in China, Japan and India ${ }^{7-11}$ but not in other countries. For example, randomised controlled trial (RCT) evidence showed that UTI was associated with a lower risk of mortality among patients with SAP compared with placebo, ${ }^{12-14}$ but not among patients with AP that was not classified as severe. No product has received such formal approval for SAP in the USA and Europe. Instead, the focus has remained mainly on the management of any known underlying conditions and the provision of supportive care (such as intravenous fluid, antibiotics, drainage therapy and enteral feeding).

The increasing incidence of AP, the potentially devastating consequences of its progression and the lack of licensed pharmacological interventions collectively raise questions about the scale of the current burden among those with the most severe disease. With such issues in mind, we conducted a systematic literature review (SLR) that aimed to provide a broad overview of the burden of illness (BOI) associated with MSAP and SAP in the USA and the European Union-5 (EU-5). A key objective of this research was to systematically collate and present relevant evidence to provide insights into the clinical challenges and outcomes specific to the most severe forms of AP.

\section{METHODS}

The SLR aimed to develop an overview of the BOI associated with MSAP and SAP by creating a framework based on the following review questions:

- What are the characteristics of patients diagnosed with MSAP and SAP, in terms of age, gender, aetiologies and comorbidities?

- What are the incidence and prevalence of MSAP and SAP? What proportion of patients with AP presentation progresses to MSAP or SAP?

- What are the clinical outcomes including mortality, morbidity and complications associated with MSAP and SAP?

- What is the quality of life (QoL) of patients diagnosed with MSAP or SAP?

- What is the economic burden of MSAP and SAP?
- What real-world interventions are being given to patients with MSAP and SAP in the context of the lack of approved specific treatments for AP, MSAP or SAP?

\section{Study identification}

The SLR followed a prespecified review protocol (online supplementary appendix A) and was conducted in accordance with the quality standards recommended by the Preferred Reporting Items for Systematic Review and Meta-Analyses (PRISMA) statement ${ }^{15}$ and the Cochrane Handbook for Systematic Reviews. ${ }^{16}$

Searches were conducted in MEDLINE (including MEDLINE In-Process) and Embase. Only studies that met all inclusion criteria were included. MSAP was defined as a separate AP severity entity beginning in $2012^{5}$; consequently, separate searches for AP and SAP were conducted to maximise the chances of identifying relevant data on MSAP and SAP and to address the heterogeneity in how these two disease groups have been defined in the recent literature.

The separate search strategies included a combination of controlled vocabulary and free-text terms, as recommended by the Cochrane Collaboration. ${ }^{17}$ Full details of the searches are described in the online supplementary appendix A. Additionally, proceedings from the previous 3 years (2015-2017) of key conferences were also manually searched. Bibliographies of all relevant SLRs identified during the evidence search were also reviewed to identify any relevant missing publications.

\section{Studies selection and data extraction}

A three-stage screening process was applied to determine the most relevant studies as defined by the protocol. First, title and abstract screening of all unique references identified in both literature databases and grey sources was reviewed against these selection criteria. Studies that reported on multiple outcomes were cross-checked to ensure that all relevant data sources on a particular outcome were considered for inclusion.

Second, owing to the high volume of evidence retrieved, additional selection criteria were applied systematically. For AP and MSAP studies, only those published after 2012 (the year of publication of the RAC) were ultimately included. For the SAP studies, those published between 2007 and 2017 were considered for inclusion.

Finally, the full-text versions of all the publications considered relevant based on the additional criteria were assessed for their suitability for inclusion and full data extraction. All publications were reviewed by one researcher and $50 \%$ of the screening decisions were validated by a second, senior researcher. Any discrepancies were resolved by a third researcher.

Relevant data were fully extracted by one investigator using a predesigned template separated by outcome. All data was validated by a second investigator and any discrepancies were resolved by a third investigator. 


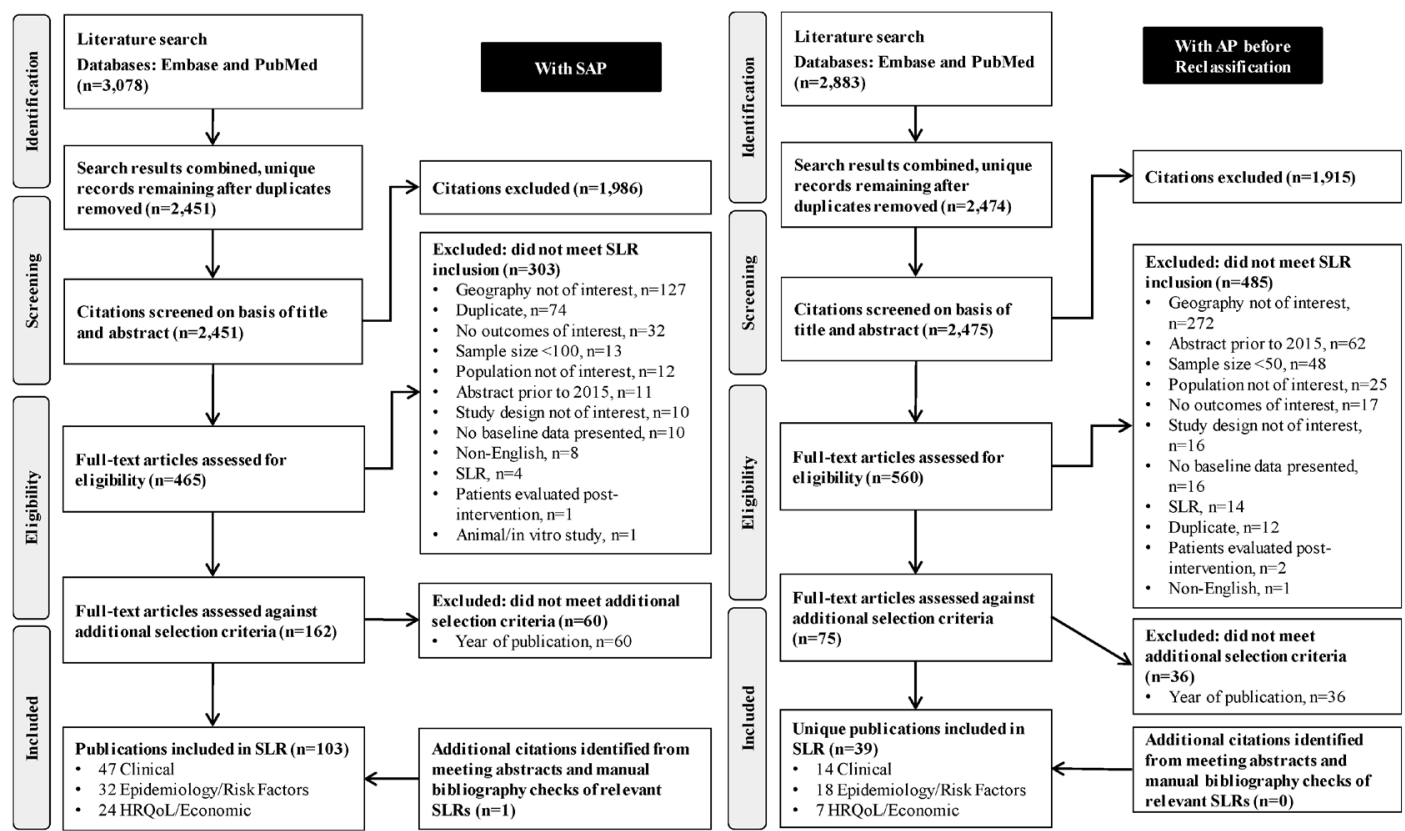

Figure 1 Preferred Reporting Items for Systematic Review and Meta-Analysis diagram of studies evaluating patients with SAP and with AP before reclassification. AP, acute pancreatitis; HRQoL, health-related quality of life; SAP, severe acute pancreatitis; SLR, systematic literature review.

\section{Synthesis of results}

During data extraction and evidence synthesis, it was noted that there was marked variation in how AP severity had been classified across included studies. This inconsistency mainly reflected differences in the time of data collection, as well as the introduction of different classification systems. Accordingly, to enable cross-study comparison and accurate presentation of outcomes by severity group, the populations included in the studies were reclassified as part of the review using the RAC 2012 criteria, where possible. If the authors had not provided such data, their definitions of various forms of AP were accepted as reported. When a study presented data for more than one severity group, these subgroup results were presented separately in the SLR for MSAP and SAP. Studies providing data on mixed-severity populations without stratification of results by severity were not included in the synthesis of results.

\section{RESULTS}

The AP and SAP searches (electronic and conference proceedings) yielded a total of 4925 unique records, of which 1024 full-text publications were reviewed. A total of 118 unique studies presenting information on the outcomes of interest for all AP severity groups across the two searches were included (figure 1). After the reclassification of populations using the RAC 2012 criteria, 19 studies (reported in 21 publications) that included MSAP and/or SAP patient populations were identified and further considered in this SLR (figures 1 and 2). Of note, 52 of the 118 studies exclusively included patients with mild AP and 47 included mixed AP severity; those were not considered further in this SLR with the exception of one study with mixed AP severity ${ }^{3}$ which provided information on the size of the SAP population subgroup. This study $^{3}$ was included in the reporting of epidemiological outcomes.

Six $^{18-24}$ (reported in seven publications) of the 19 included studies were US based. Of the 13 EU-5 studies, five $^{325-28}$ were conducted in the UK, three each in Germany ${ }^{29-31}$ and Italy, ${ }^{32-34}$ and one each in France ${ }^{35}$ and Spain. ${ }^{36}$ Overall, most studies were of a retrospective design (13 studies),${ }^{321-2325-33}$ were based on single-centre hospitals (13) ${ }^{18-22}$ 24-26 282931333536 and were principally tertiary referral units for which the reporting was exclusively on patients with SAP (10). $.^{22} 2325-3133$ The sample size of these studies varied considerably, from $20^{25}$ (in a single-centre UK study) to 2677 (for a study based on the UK national intensive care unit (ICU) database) ${ }^{27}$ Four studies $^{19} 212436$ (reported in five publications) presented subgroup information for patients with MSAP and these are presented separately.

\section{Characteristics, aetiology and comorbidities of patients with MSAP and SAP}

Most of the patients with MSAP and SAP in the included studies were men $(51 \%-71.4 \%)^{2133}$ and all were aged in their 50s (52.5-65.8) ${ }^{22} 32$ (tables 1 and 2). Gallstone/ biliary disease and alcohol were the most common aetiological factors in both the USA and EU-5 studies. Most specifically, among the SAP studies, gallstone/biliary aetiology was present in $31 \%{ }^{29}-45 \%{ }^{19}$ of patients in the USA and $33 \%^{24}-61.1 \%^{34}$ of those in the EU-5 studies, whereas alcohol aetiology was present in $17 \%^{22}-33 \%{ }^{24}$ of patients in the USA and $8.4 \%^{34}$ in the EU-5. Although, idiopathic aetiology was not widely reported in the included studies, 

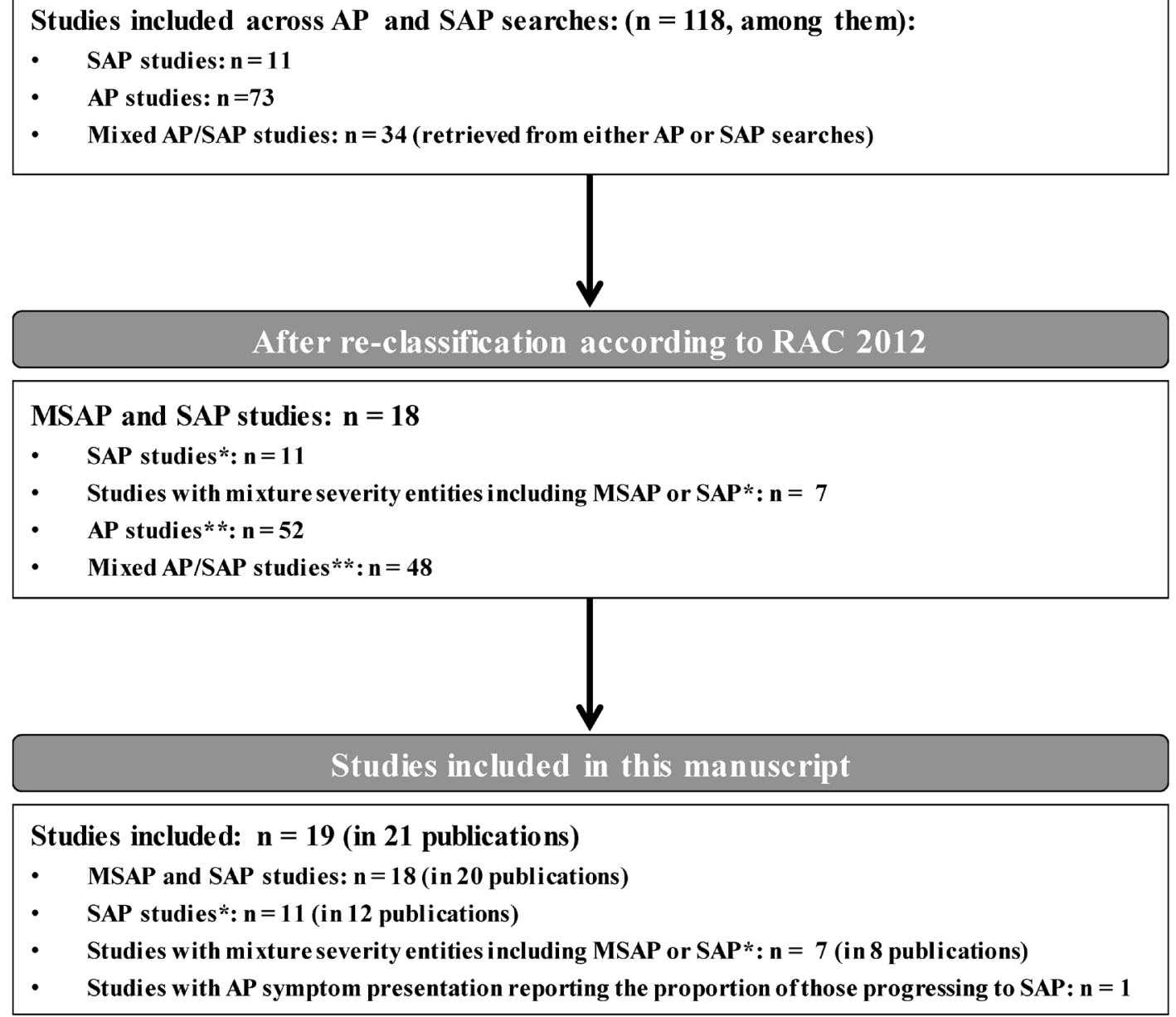

Figure 2 Diagram of included studies evaluating patients with MSAP and SAP after reclassification. * Only studies reporting data of MSAP or SAP according to RAC 2012 are included in this manuscript. †Findings relating to AP or mixed AP/SAP studies are not summarised in this manuscript. AP, acute pancreatitis; MSAP, moderately severe acute pancreatitis; RAC, revised Atlanta classification; SAP, severe acute pancreatitis.

it still accounted for up to $20 \%^{24}$ (USA) and $13.6 \%^{36}$ (EU-5) of SAP cases. A similar trend in idiopathic aetiology was identified in the studies including patients with MSAP. ${ }^{19} 212436$

\section{Epidemiology}

Given the variations in diagnosis and severity assessment criteria of AP across studies over previous decades, the rapidly evolving features of disease progression, and the fact that most studies of patients with SAP were conducted in single-centre specialist hospitals, it is difficult to derive definitive data on key aspects of the epidemiology of MSAP or SAP, particularly in the USA.

In our review, only one EU-5 study ${ }^{3}$ reported on the incidence of patients with SAP who required critical care admission (data collected between 2009-2012 and found this to be 5.9/100 000 per year (table 3). Another study from Italy reported that the proportion of AP patients progressing into SAP to be $14.2 \% .^{34}$

\section{Mortality}

Overall, mortality and morbidity increased with disease severity across the studies (tables 4 and 5). Results from four studies ${ }^{19212436}$ presenting within-study comparisons of outcomes by AP severity group provide more reliable estimates of differences using a relatively homogeneous population (in terms of the study setting, years of data collection, AP severity classification systems) compared with cross-study comparisons. In three of these studies, the risk of death for patients with MSAP was $0 \% 192436$ compared with $21 \%-40 \%^{19} 24$ for patients with SAP. A similar pattern regarding SAP mortality was found across the other 14 studies, ${ }^{1822} 2325-35$ with the risk ranging from $13.6 \%^{27}$ to $41.9 \%{ }^{27}$; EU-5 estimates on mortality were higher for SAP than US estimates (41.9\%). ${ }^{27}$ However, the available EU-5 estimates on SAP mortality need to be viewed with caution because of the lack of reported information to allow reclassification of patients according to the RAC 2012 criteria. 


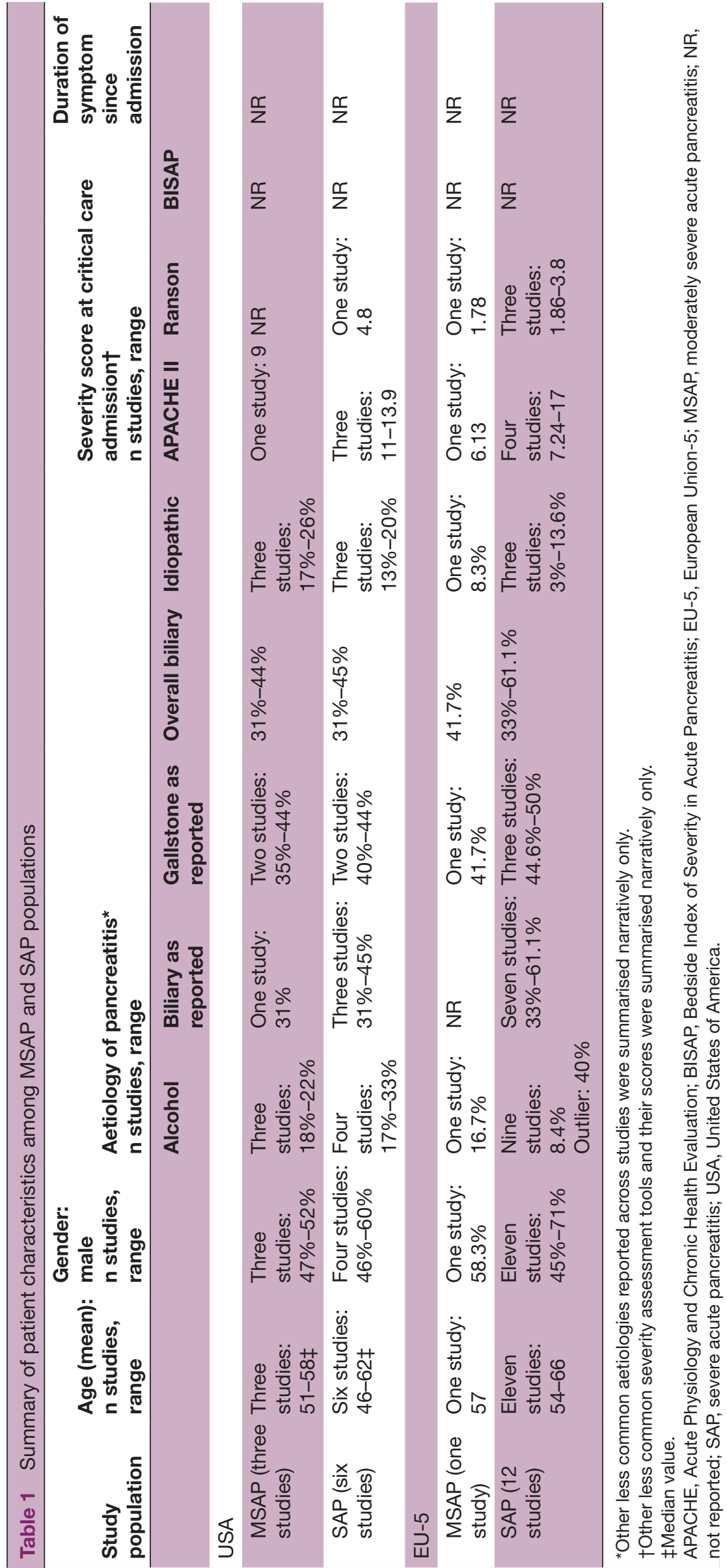




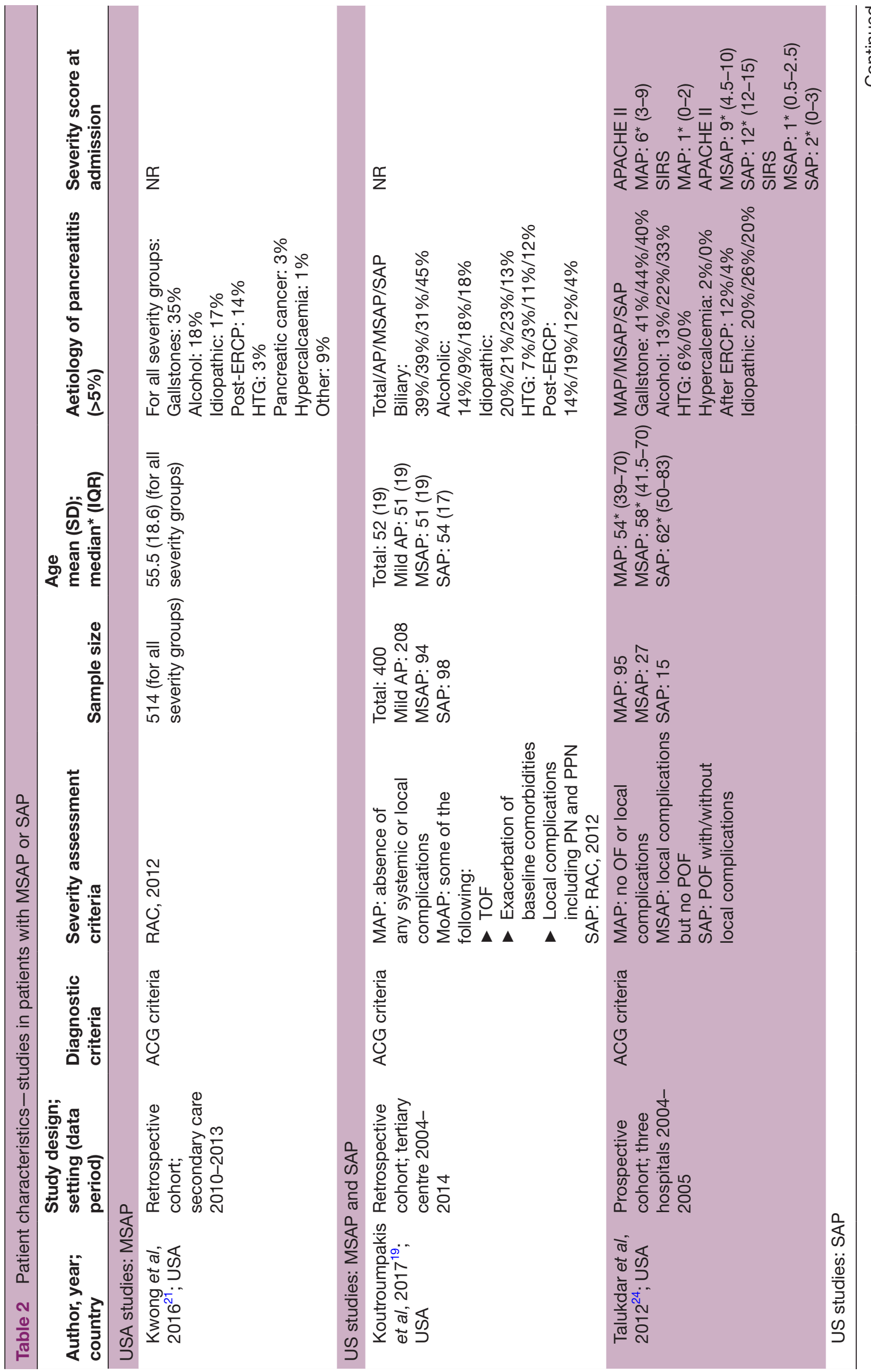




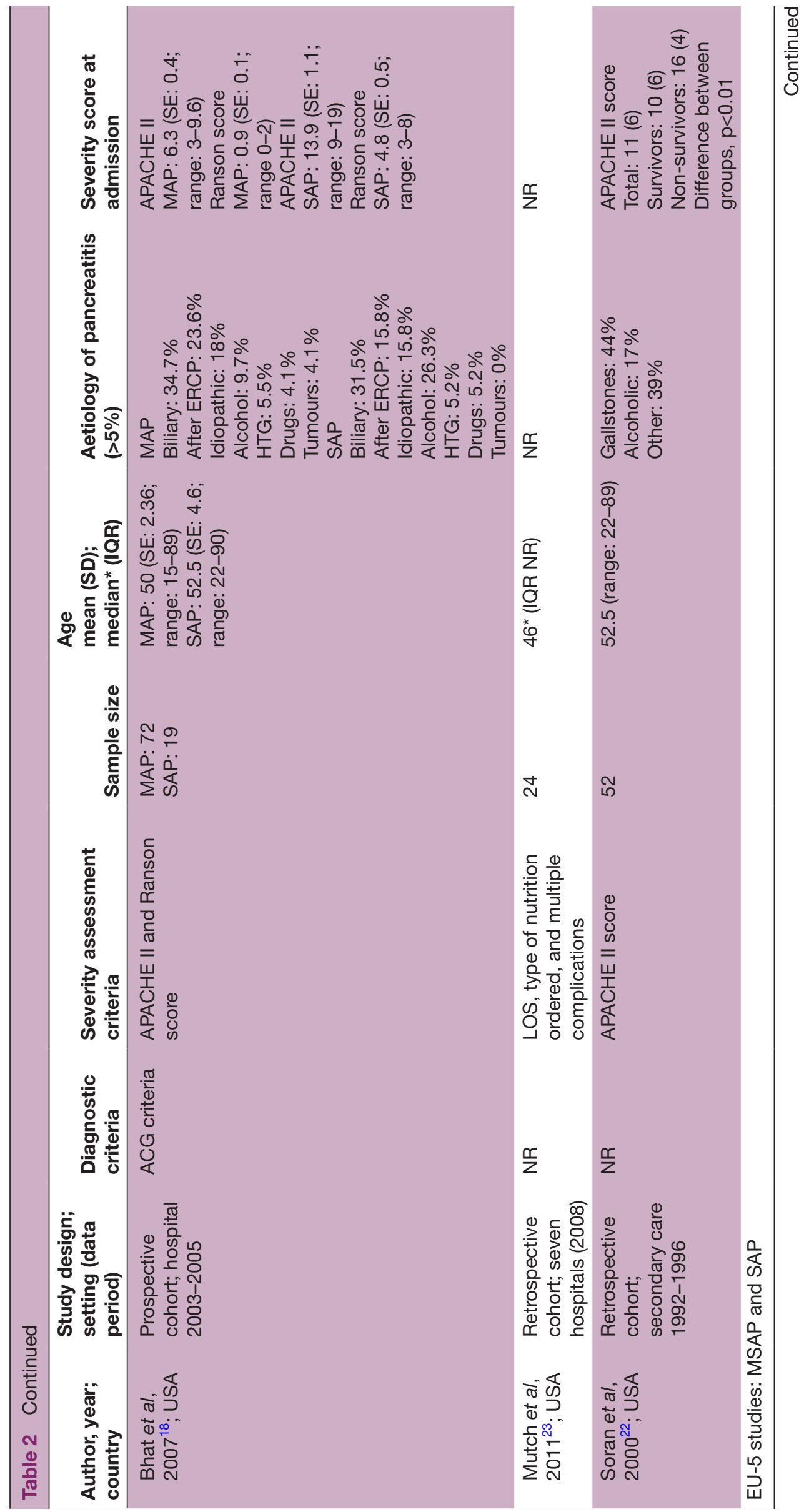




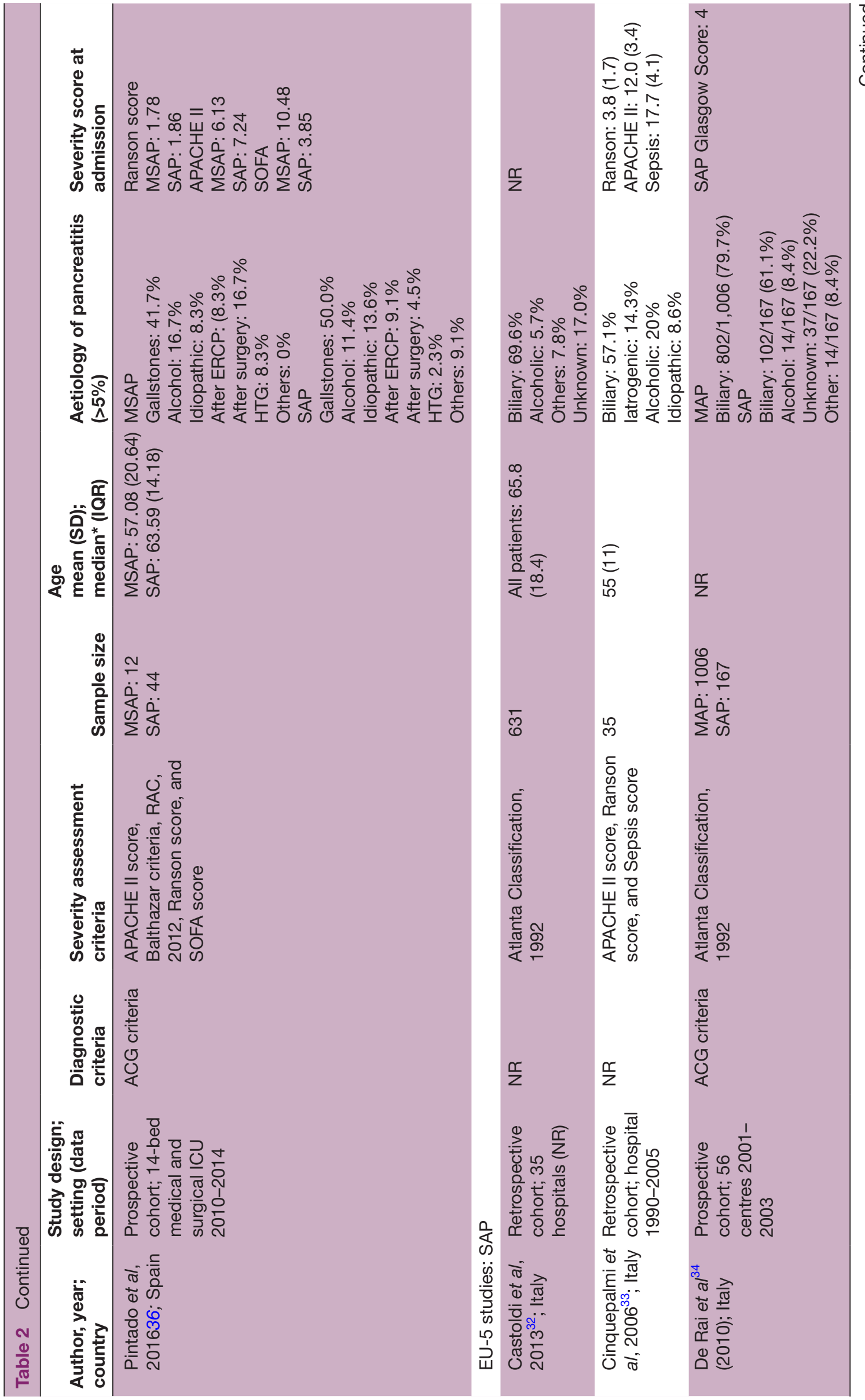

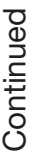




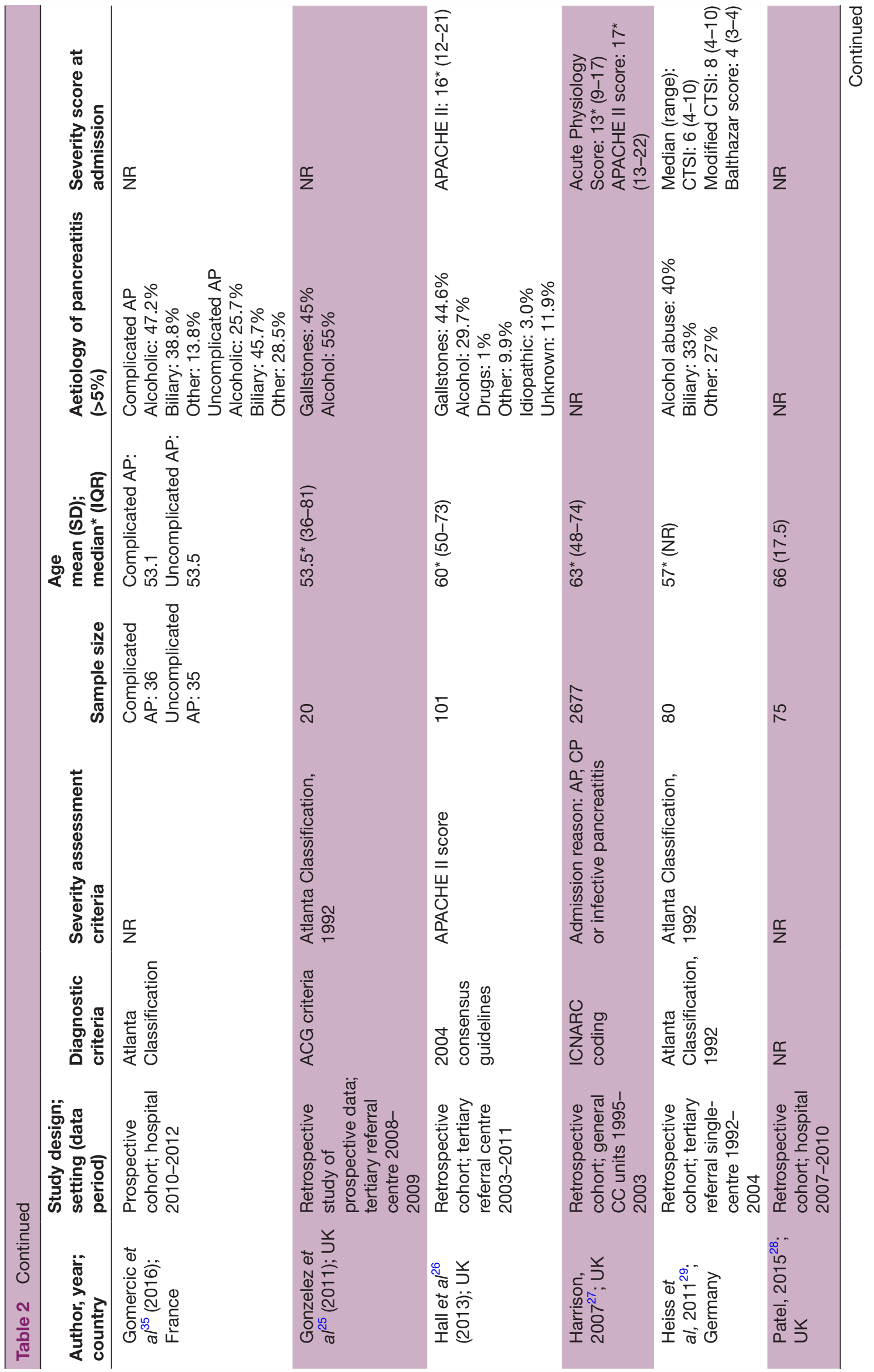



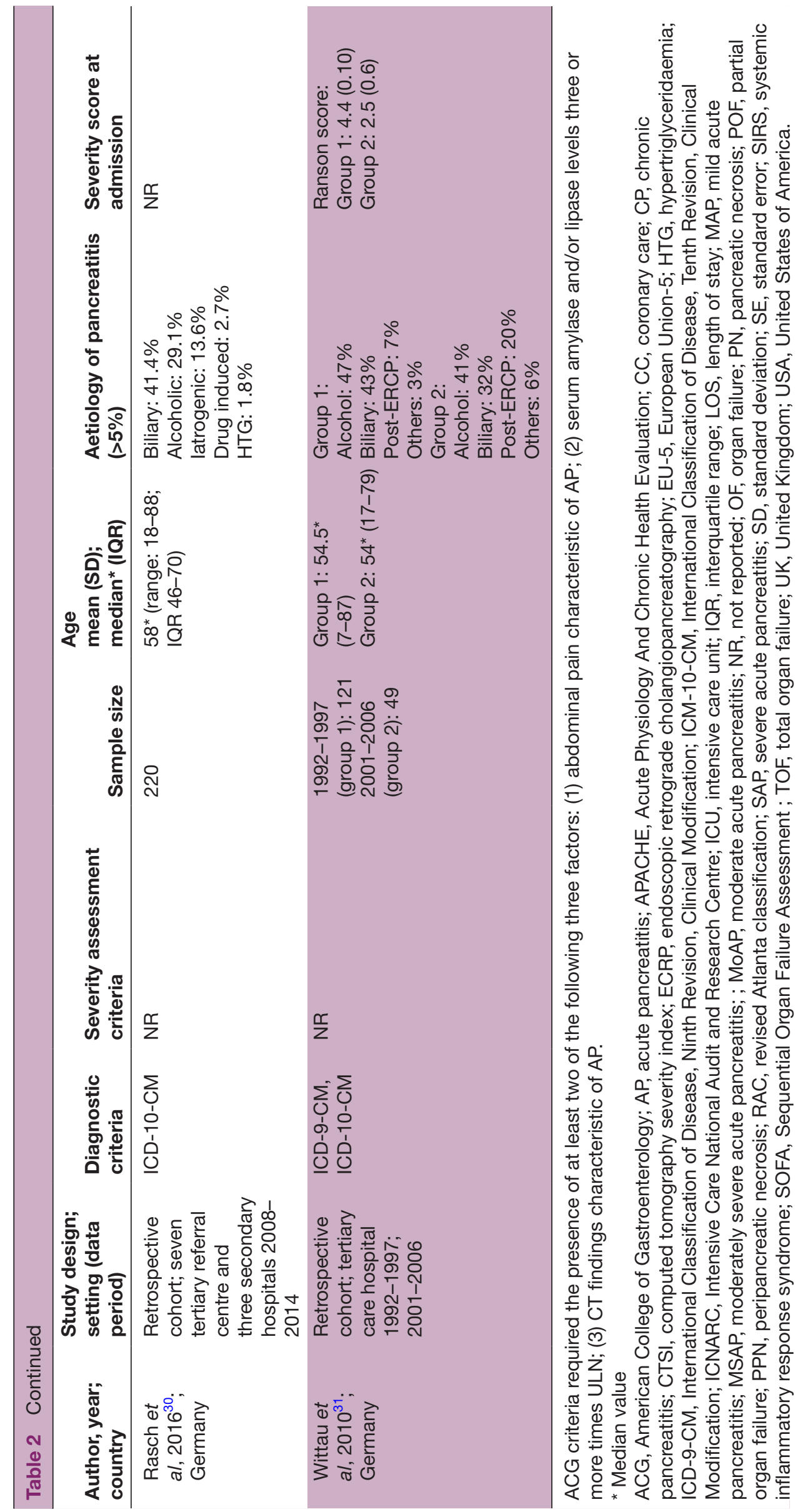


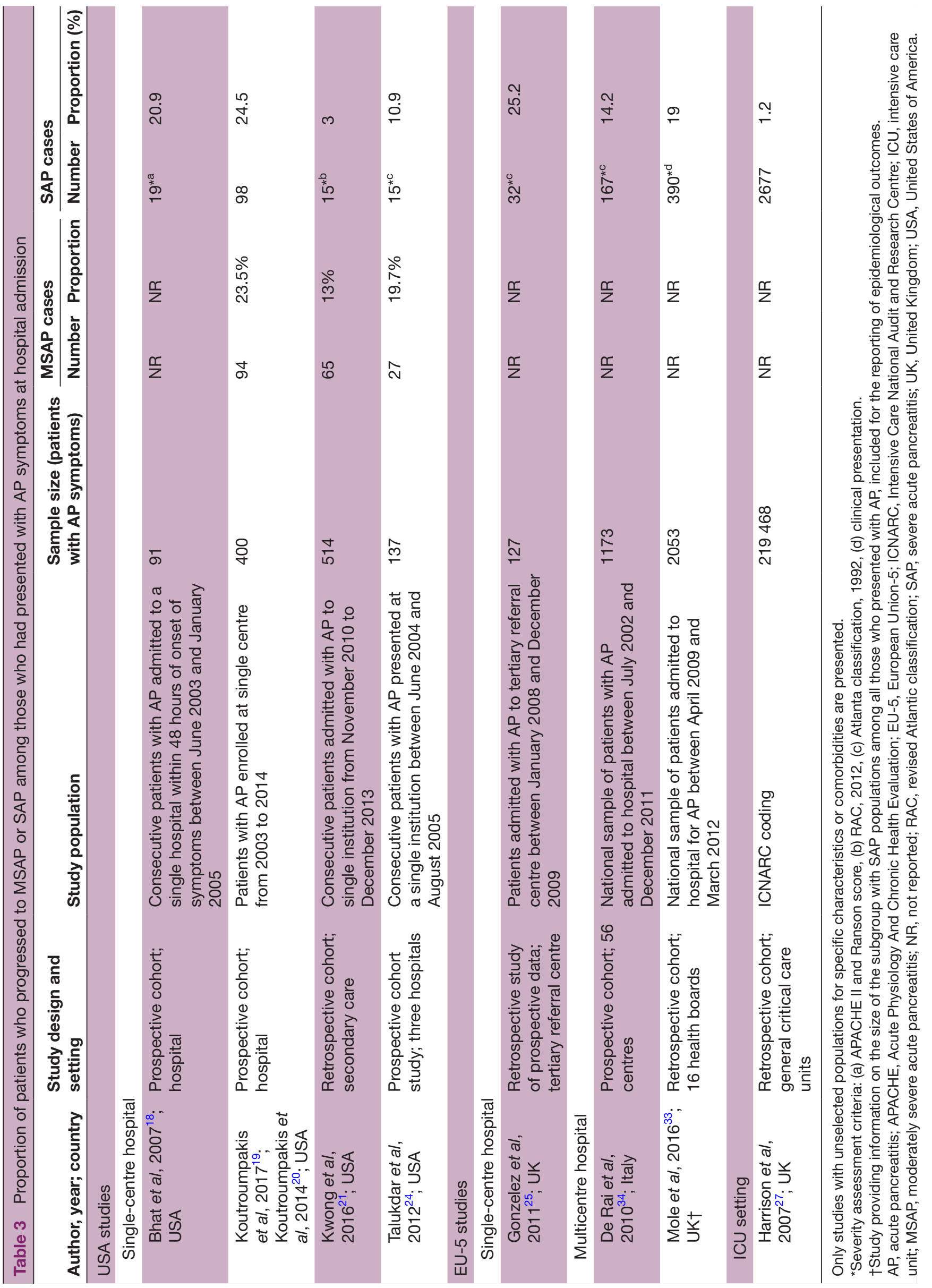

임 
Table 4 Summary of clinical outcomes: complications and mortality

\begin{tabular}{|c|c|c|c|c|c|c|}
\hline & $\begin{array}{l}\text { IPN } \\
\text { (n studies; } \\
\text { range) }\end{array}$ & $\begin{array}{l}\text { Surgery due } \\
\text { to pancreatic } \\
\text { necrosis }\end{array}$ & $\begin{array}{l}\text { Pancreatic } \\
\text { pseudocysts }\end{array}$ & $\begin{array}{l}\text { Other long- } \\
\text { term outcomes } \\
\text { of surviving } \\
\text { patients }\end{array}$ & $\begin{array}{l}\text { Hospital } \\
\text { mortality }\end{array}$ & $\begin{array}{l}\text { Long-term } \\
\text { mortality }\end{array}$ \\
\hline \multicolumn{7}{|l|}{ USA } \\
\hline $\begin{array}{l}\text { MSAP (as defined } \\
\text { by the authors; two } \\
\text { studies) }\end{array}$ & $1(9 \%)$ & NR & NR & NR & $1(0 \%)$ & NR \\
\hline $\begin{array}{l}\text { SAP (as defined by the } \\
\text { authors; four studies) }\end{array}$ & $3(21.1 \%-32 \%)$ & NR & NR & NR & $\begin{array}{l}4(21 \%- \\
40 \%)\end{array}$ & NR \\
\hline \multicolumn{7}{|l|}{ EU-5 } \\
\hline $\begin{array}{l}\text { MSAP (as defined by } \\
\text { the authors; one study) }\end{array}$ & $1(10 \%)$ & $1(16.7 \%)$ & $1(0 \%)$ & NR & $1(0 \%)$ & NR \\
\hline $\begin{array}{l}\text { SAP (as defined by the } \\
\text { authors; } 11 \text { studies) }\end{array}$ & $\begin{array}{l}7(4.8 \%-11.4 \%) \\
\text { Outlier: } 40 \%\end{array}$ & $\begin{array}{l}4(4.8 \%-10.5 \%) \\
\text { Outlier: } 25 \%\end{array}$ & $1(2.3 \%)$ & 2 (4.1\%-93\%) & $\begin{array}{l}12(17.8 \% \% \\
-41.9 \%) \\
\text { Outlier: } 5 \%\end{array}$ & $\begin{array}{l}\text { Mean follow-up } \\
49 \text { months } \\
1(12.3 \%)\end{array}$ \\
\hline
\end{tabular}

EU-5, European Union-5; IPN, infected pancreatic necrosis; MSAP, moderately severe acute pancreatitis; NR, not reported; SAP, severe acute pancreatitis; USA, United States of America.

The longer term mortality for patients with SAP (4 years postdischarge) was $12.3 \%$ as reported by one study. ${ }^{32}$

\section{Morbidity and complications}

A total of 15 studies (11 from the EU-5 and four from the USA) reported outcomes relating to morbidity or complications associated with either MSAP (four studies) 19212436 or SAP (13 studies) ${ }^{18-2024252729-36}$ (table 4). Reported high morbidity across studies included severe systemic inflammatory response syndrome (SIRS; estimated to occur in $65 \%$ of US patients with $\mathrm{SAP}^{19}$; no data reported for patients with SAP in the EU-5), multisystem OF (US studies: $47.4 \%-60 \%{ }^{18}{ }^{19}$; EU-5 studies: generally $25 \%-36.4 \%,{ }^{31}{ }^{36}$ with one small study $(n=35)^{35}$ reporting a significantly lower occurrence of $4.2 \%$ among patients with SAP) and admission to critical care (US studies: 80\%-93\%, EU-5 studies: 60.7\% ). ${ }^{19} 2435$ Limited evidence was found for the proportion of patients with SAP with infected pancreatic necrosis (IPN; 21.1\%-32\%) ${ }^{18} 19$ in the USA or those needing surgery due to pancreatic necrosis (PN; $4.8 \%-10.5 \%)^{2734}$ in the EU-5.

Although the morbidity of MSAP was not found to be as high as in patients with SAP, limited evidence (mainly from US studies) showed that the condition was often still associated with poor outcomes. For instance, $48 \%{ }^{19}$ had SIRS, $26.1 \%^{21}$ had OF and up to $23 \%{ }^{21}$ were admitted to the ICU. Similarly, since some studies did not provide sufficient information to allow reclassification of patients according to RAC 2012, estimates from the EU-5 studies should be interpreted with caution.

\section{Humanistic outcomes}

Limited evidence was identified on the humanistic burden of SAP from one US retrospective study ${ }^{22}$ and no studies reporting on such outcomes were identified for MSAP. The US retrospective study ${ }^{22}$ included surviving patients with SAP who required ICU admission (at a median of 42 months follow-up) and showed that QoL (as measured by the 36-item Short Form survey) appeared to be acceptable compared with that of their healthy peers.

\section{Economic outcomes}

Twenty-three studies (12 from the USA and 11 from the EU-5) 1922 24-27 293033 36-48 reporting on economic outcomes related to SAP and MSAP were identified in this review. One study in patients with SAP reported the mean inpatient costs of US\$136 730 per patient (cost year not reported (NR)) for those who were transferred to the ICU and did not survive, compared with US\$88 434 for those who did survive. ${ }^{22}$

In the USA, patients with MSAP stayed in the hospital for a range of $6^{24}-12^{19}$ days; this duration was much shorter than for those with SAP (16.5-40 days). ${ }^{22}$ This wide span for the SAP group reflects differences in severity classification and the type of complications involved. More specifically, patients with longer hospital stays were those with the most severe forms of disease. This included patients with peri-PN or PN, IPN (15-21 days in hospital) ${ }^{38} 45$ compared with those without these complications: (4 days) ${ }^{44}$; multisystem OF (19-30 days) ${ }^{42}$ compared with those without (7-9 days)); isolated renal or pulmonary failure ( 24.7 and 28.8 days, respectively) ${ }^{37}$ and those requiring admission to the ICU (38-40 days). ${ }^{22}$

In general, studies from the USA evaluating ICU length of stay (LOS) reported similar results: 2.5-4 days ${ }^{19}{ }^{24}$ for MSAP and 4.5-14 days ${ }^{19} 24$ for SAP. The one exception was one a retrospective study involving patients with SAP in which those who survived hospital admission for AP had an ICU LOS of 15 days and those who did not stayed in the ICU for 28 days. ${ }^{22}$ This reflects the variations in disease severity and the associated number of complications across studies.

There was a similar trend in the length of ICU stay across the EU-5 studies (MSAP: 7.6 days (study not systematically identified $)^{36}$ and SAP: $3.8^{27}-28.4$ days; 


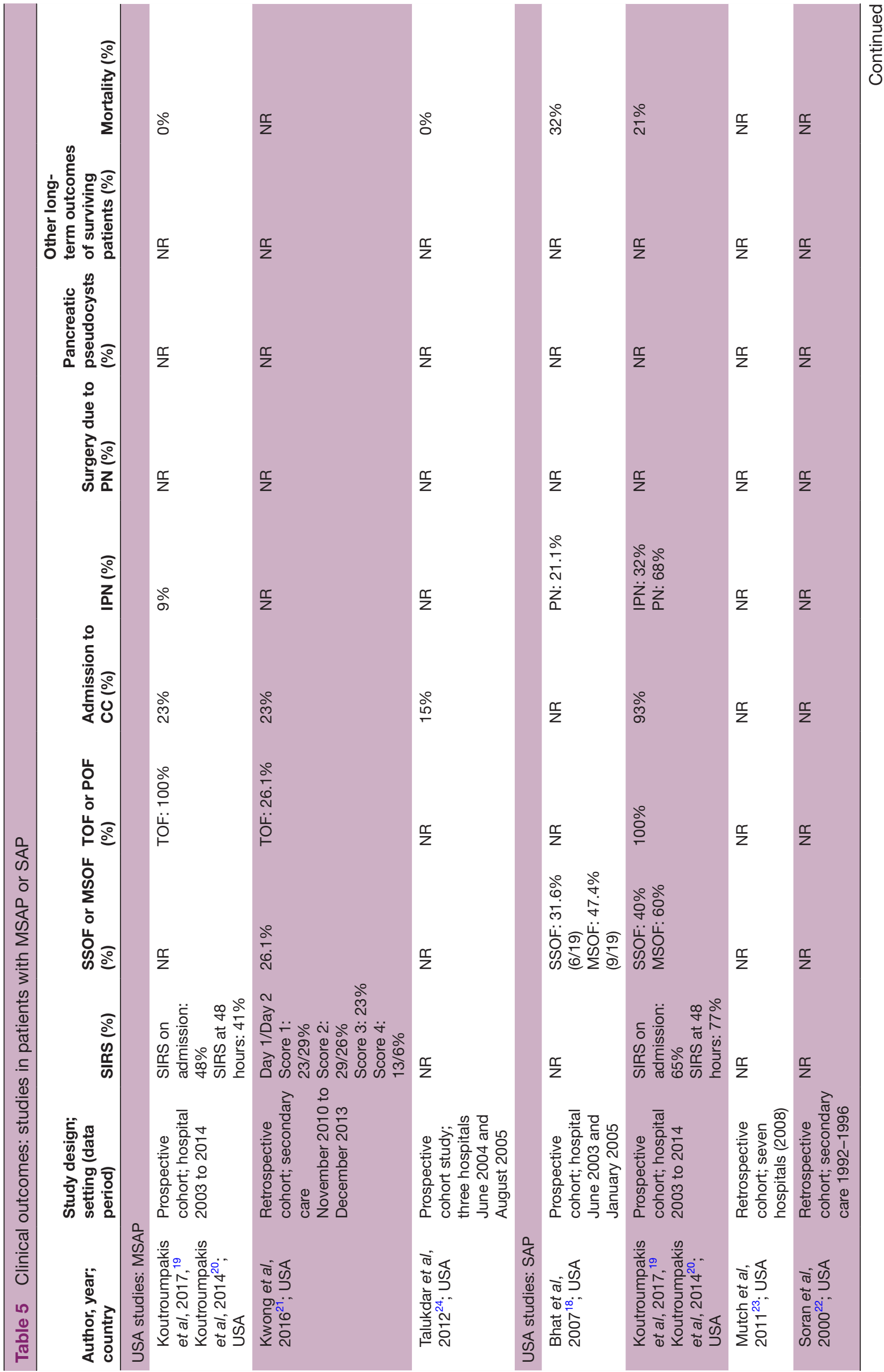




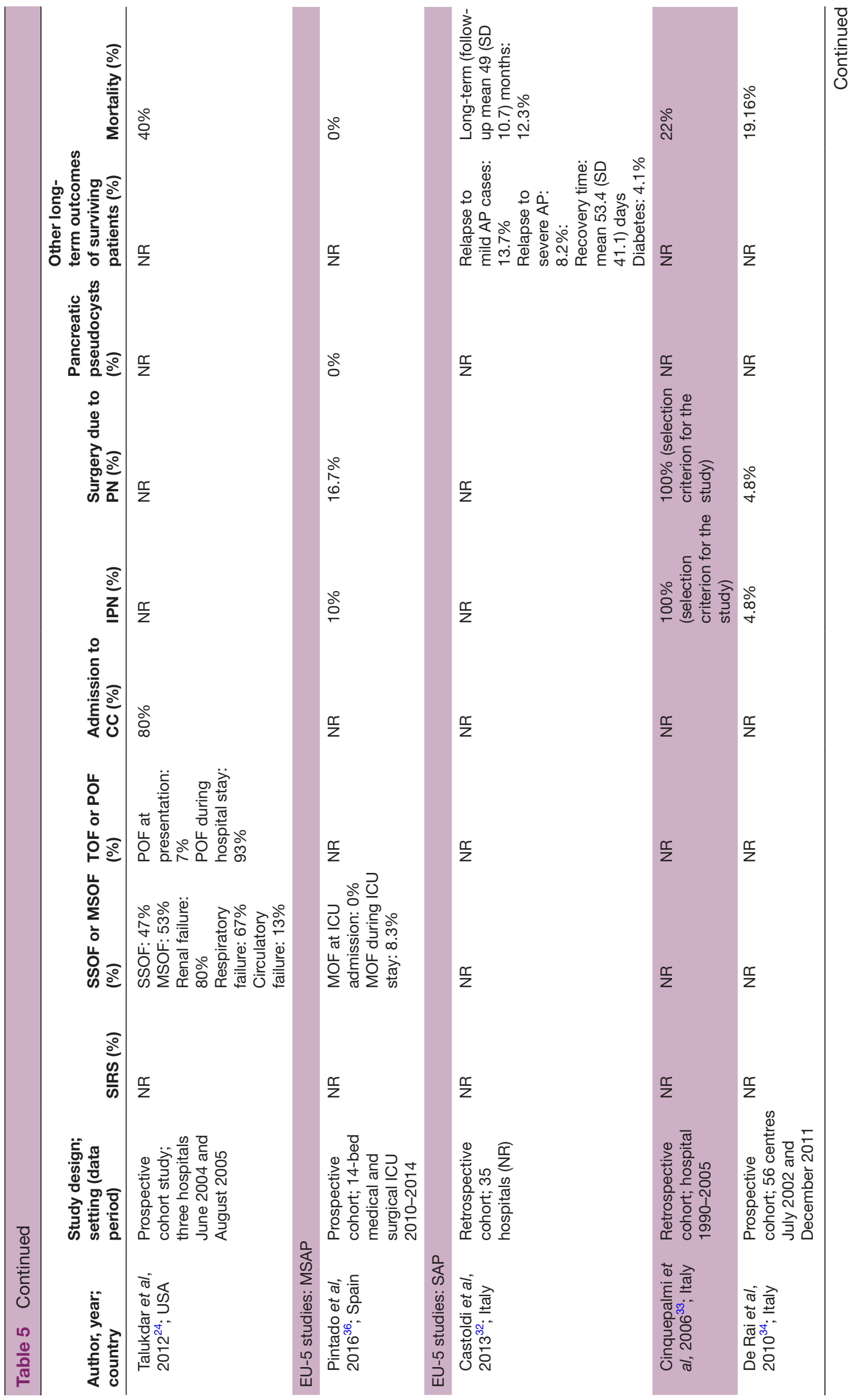




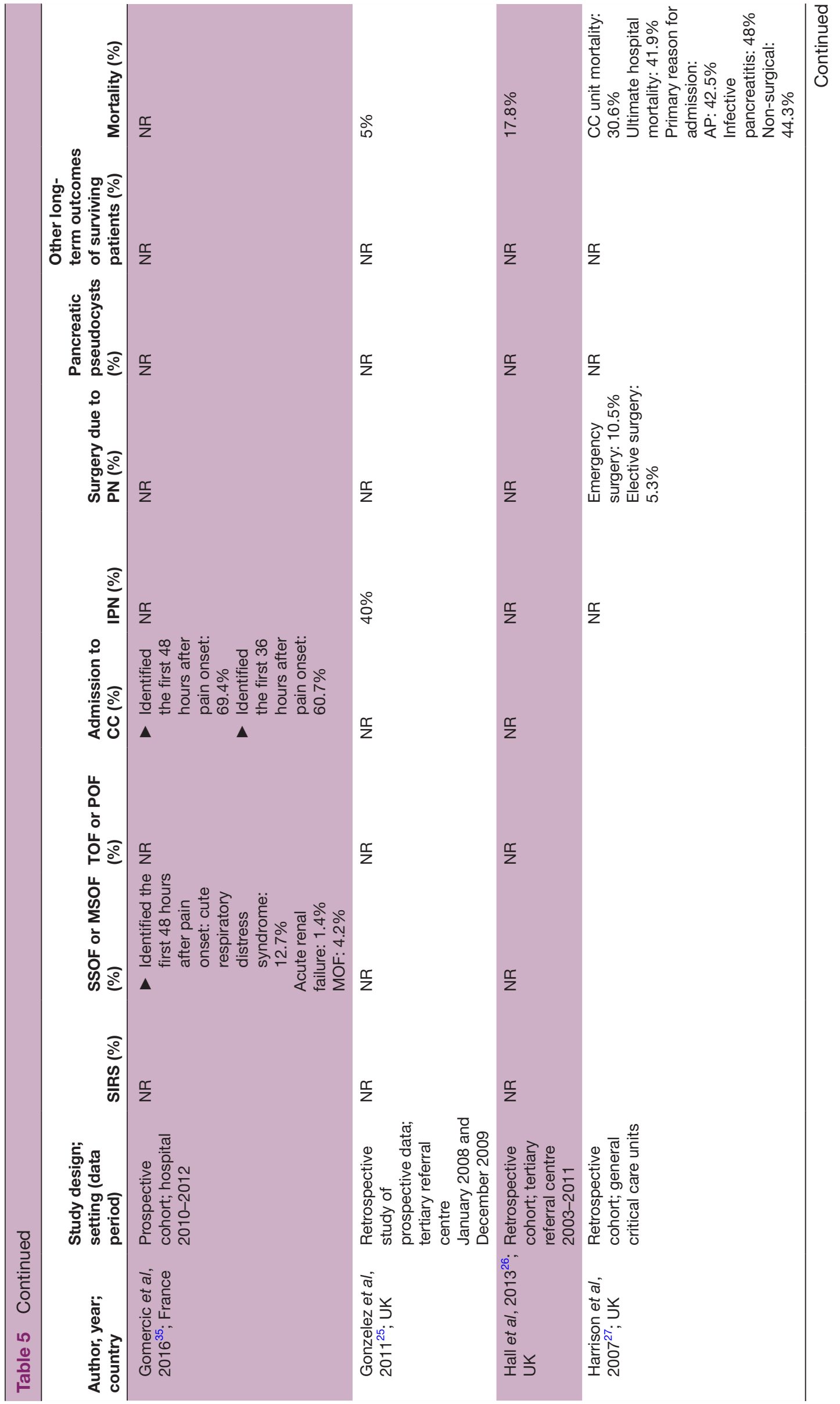



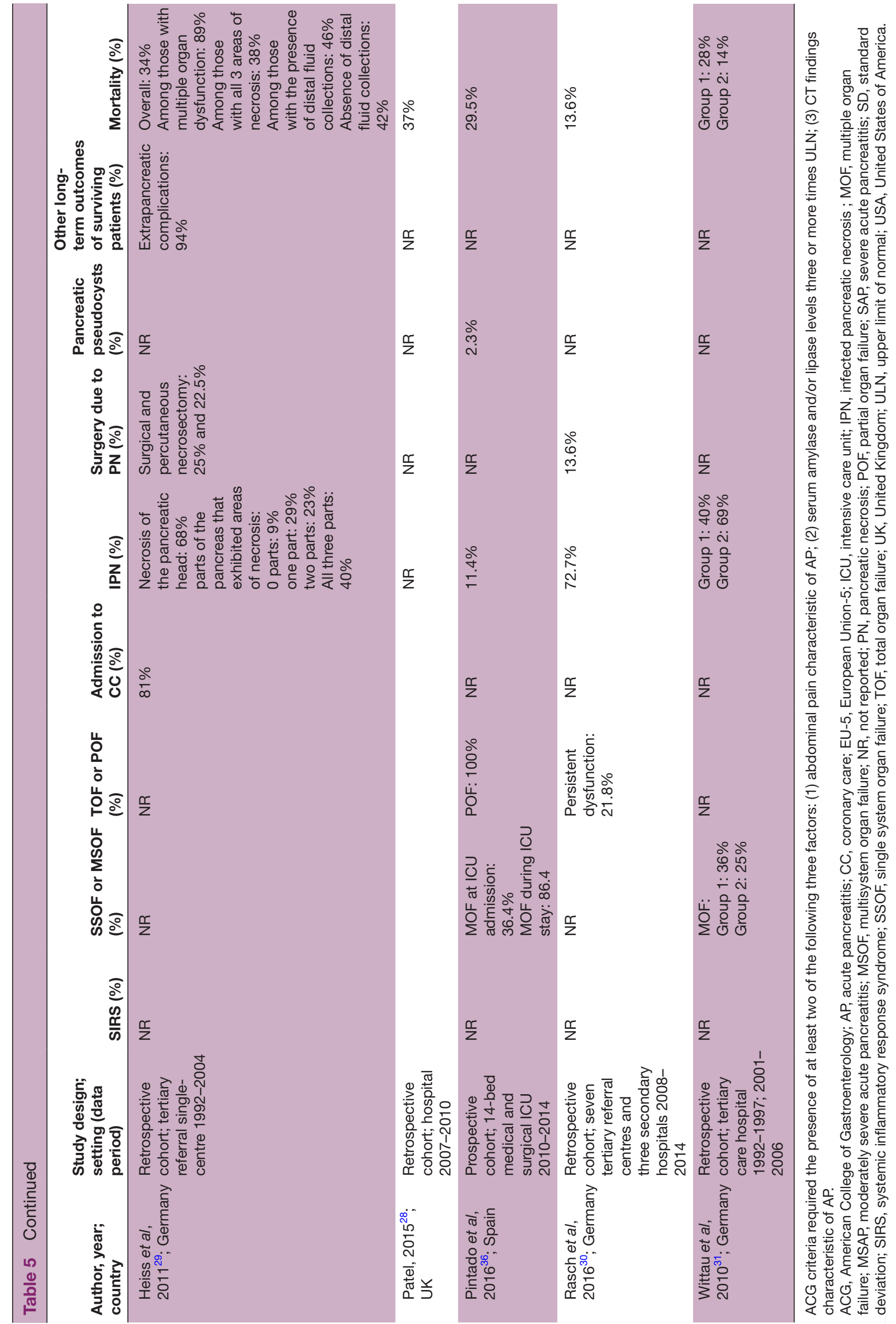
both studies not systematically identified) ${ }^{36}$ In patients with SAP, most studies reported hospital LOS ranging from 21 to 51 days (all studies not systematically identified). ${ }^{25} 29304748$ More specifically, patients with $\geq 100$ $\mathrm{mL}$ extrapancreatic necrosis volumes and those rated as severe on the CT severity index had the highest hospital LOS (39.2 and 59.8 days, respectively; study not systematically identified). ${ }^{46}$ However, a few studies reported shorter LOS in patients who survived admission to the ICU (15 days) ${ }^{27}$ presurgery patients for IPN (12.6 days) ${ }^{33}$ and patients admitted to the ICU in a tertiary referral centre ( 4 days; study not systematically identified). ${ }^{26}$

\section{Need for interventions for patients with MSAP and SAP}

In US studies, the proportion of patients with MSAP given supportive interventions currently available for AP (eg, nutritional support, drainage, mechanical ventilation (MV)) was $3.72^{24}-51 \%^{19}$; however, as expected, the proportion was higher for those with SAP $(47 \%-90 \%) .{ }^{1921}$

The use of supportive interventions in the EU-5 studies followed the same trend as the USA, with patients with SAP being more likely to require different interventions (such as MV, vasoactive support, percutaneous or transgastric drainage or renal replacement therapy $(5 \%-94.7 \%)^{26}{ }^{36}$ compared with patients with MSAP $(0 \%-16.7 \%){ }^{36}$ Among patients with SAP, those who required such interventions most frequently were those with PN $(89.5 \%)^{30}$ and those who developed complications during admission to the ICU $(81.8 \%-94.7 \%){ }^{36}$ However, no significant differences were found in surgery rates between studies of patients with SAP $(5 \%-26.7 \%)^{25} 26$ and studies of patients with mixed AP/ SAP (data not presented).

\section{DISCUSSION}

To our knowledge, this SLR provides a unique overview of the BOI associated with severe forms of AP, spanning epidemiological, clinical, humanistic and economic outcomes. It surpasses the scope of previous overviews on AP by taking an in-depth look at the BOI associated with MSAP and SAP, as defined by the RAC. In doing so, the results of this SLR not only highlight the high burden associated with SAP and with most outcomes for MSAP but also underline the key differences in the outlook of the two conditions.

Evidence on the clinical and economic consequences of these more severe forms of AP showcases their significant additional burden. Studies including patients with SAP typically reported a much higher proportion of patients experiencing adverse clinical outcomes compared with patients with MSAP, even though there was wide variation in the results primarily due to the heterogeneous patient populations across studies. This also holds true for other outcomes including comorbidities and complications, economic burden and the use of interventions targeting complications or supportive care; these trends were generally similar in the USA and the EU-5.
The data clearly demonstrates that despite recent advances in standardising how severe forms of AP are recognised and classified, many patients progress to SAP, a condition that is often fatal. That this remains common, even in industrialised countries with sophisticated healthcare systems, accentuates how little clinicians can currently offer patients to prevent or effectively manage such disease progression. The lack of such targeted treatment is likely to represent an ever-growing problem given current epidemiology trends towards more common global occurrence of AP.

\section{Strength and limitations}

The major strength of this study is the systematic approach of identification and collection of the most relevant evidence to facilitate cross-study comparisons. This was achieved by reclassifying patients based on severity criteria using the most recent international classification tool (RAC 2012). However, because of the variations in diagnosis criteria and severity assessment of AP across studies, some that did not report data on persistent OF (single or multiple, lasting for $\geq 48$ hours) could not be reclassified using the RAC 2012. It is possible there was an under-reporting of the occurrence of SAP or complications related to SAP in those studies. On the other hand, for SAP studies (as defined by the authors) published before 2012, there could be an overestimation of the occurrence of SAP because their categorisation of this condition may have included some patients who would now be classified as having MSAP according to RAC 2012 criteria. The assessment of the extent to which such underestimation or overestimation occurred was beyond the scope of the review.

This study was also limited by scarce data on outcomes for MSAP, which is not surprising given that this severity category was only created in 2012 by the RAC. Further research is needed to determine to what extent some of the aggressive interventions commonly used for patients with SAP (such as surgeries, drainage, renal replacement therapy and catheterisation) are necessary for patients with MSAP which will result to limiting complications related to these interventions and hospital treatment costs.

There is also only limited evidence on key epidemiological features of AP because of the lack of data on the true population prevalence of MSAP and SAP in this study. It is key to identify the proportion of patients who initially appear with a mild form and later progress to more serious forms of disease (MSAP, SAP) to investigate the epidemiology of AP. This is particularly important for identifying the population size for potential targeted preventive interventions, potential transfer to the ICU for specialist treatment and active interventions. Ideally, a prospective-based, multicentre study which follows patients who present with AP symptoms and further develop severe forms of the disease will provide data with more generalisable results for the MSAP and AP population size. However, data in the literature was scarce. 
There was insufficient data assessing economic burden-only limited evidence was found on the inpatient costs for patients with SAP who were transferred to the ICU, and no data were found for patients with MSAP. Similarly, the evidence was sparse on the humanistic consequences of SAP, a crucial requirement for understanding the impact of the condition on patients and carers.

Lastly, given the variations across studies in terms of setting, baseline patient characteristics and diagnostic/ disease severity criteria, meta-analyses of the results were not possible.

\section{CONCLUSION}

Early and accurate classification of the severity of AP is crucial for managing the disease and preventing its progression. Evidence shows that after the initial 48-72 hours, the progression of AP to SAP may be fully established and multisystem OF may be inevitable. Despite the advances in scoring systems to more accurately recognise AP severity, more than $15 \%-20 \%$ of patients with AP will develop SAP and up to $40 \%$ of this subgroup will die as a result. This and other aspects of the BOI associated with SAP, and to a lesser extent, MSAP highlight the limitations of current therapy, particularly the lack of approved interventions that target disease progression.

\section{Acknowledgements Colleen Dumont from Evidera also provided writing and editing assistance.}

Contributors GS and JP contributed to the study design. GS was responsible for the data analysis. GS and YG contributed to the data collection and drafting of the manuscript. JP was responsible for the study conception. II and JP contributed to the critical revision of the manuscript. All authors contributed to the data interpretation.

Funding Takeda provided the funding for the study and for the manuscript. Competing interests None declared.

Patient consent for publication Not required.

Provenance and peer review Not commissioned; externally peer reviewed.

Data sharing statement № additional data are available.

Open access This is an open access article distributed in accordance with the Creative Commons Attribution Non Commercial (CC BY-NC 4.0) license, which permits others to distribute, remix, adapt, build upon this work non-commercially, and license their derivative works on different terms, provided the original work is properly cited, appropriate credit is given, any changes made indicated, and the use is non-commercial. See: http://creativecommons.org/licenses/by-nc/4.0/.

\section{REFERENCES}

1. Afghani E, Pandol SJ, Shimosegawa T, et al. Acute PancreatitisProgress and challenges: a report on an international Symposium. Pancreas 2015;44:1195-210.

2. Hamada S, Masamune A, Kikuta K, et al. Nationwide epidemiological survey of acute pancreatitis in Japan. Pancreas 2014;43:1244-8.

3. Mole DJ, Gungabissoon U, Johnston P, et al. Identifying risk factors for progression to critical care admission and death among individuals with acute pancreatitis: a record linkage analysis of Scottish healthcare databases. BMJ Open 2016;6:e011474.

4. Peery AF, Dellon ES, Lund J, et al. Burden of gastrointestinal disease in the United States: 2012 update. Gastroenterology 2012;143:1179-87.

5. Banks PA, Bollen TL, Dervenis C, et al. Classification of acute pancreatitis - 2012: revision of the Atlanta classification and definitions by international consensus. Gut 2013;62:102-11.
6. Working Group IAPAPAAPG. IAP/APA evidence-based guidelines for the management of acute pancreatitis. Pancreatology 2013;13(4):e1-15.

7. China/CFDA, 2015. Available: https://db.yaozh.com/pijian?comp rehensivesearchcontent=ulinastatin\&

8. India/CDSCO N, 2013. Available: http://www.cdsco.nic.in/ writereaddata/NDAC\%20Minutes/Gastroenterology.pdf

9. Japan/PMIDA, 1994. Available: https://db.yaozh.com/pmda?comp rehensivesearchcontent=ulinastatin\&

10. Kimura Y, Takada T, Kawarada Y, et al. JPN guidelines for the management of acute pancreatitis: treatment of gallstone-induced acute pancreatitis. J Hepatobiliary Pancreat Surg 2006;13:56-60.

11. Lee TH. Diagnosis and treatment of acute pancreatitis. Korean $J$ Med 2015;89:494-506.

12. Abraham $P$, Rodriques J, Moulick N, et al. Efficacy and safety of intravenous ulinastatin versus placebo along with standard supportive care in subjects with mild or severe acute pancreatitis. $J$ Assoc Physicians India 2013;61:535-8.

13. Cai W. The effect of ulinastatin in 32 acute pancreatitis patients. Suzhou University J Med Sci 2006;26:1013-4.

14. Zhang SP. Effect of ulinastatin on serum C-reactive protein in acute pancreatitis. Chin J Crit Care Med 2010;48:10.

15. Moher D, Liberati A, Tetzlaff J, et al. Preferred reporting items for systematic reviews and meta-analyses: the PRISMA statement. BMJ 2009;339:b2535.

16. PT. H, S G. Cochrane Book Series: Cochrane Handbook for Systematic Reviews of Interventions, 2008.

17. Training C. Cochrane Handbook for Systematic Reviews of Interventions. In: Handbook Editors' Update - Hardcopy 2nd edition due early 2019 - New chapters and content, July 2018.

18. Bhat YM, Papachristou GI, Park JS, et al. Functional polymorphisms of the GSTT-1 gene do not predict the severity of acute pancreatitis in the United States. Pancreatology 2007;7:180-6.

19. Koutroumpakis E, Slivka A, Furlan A, et al. Management and outcomes of acute pancreatitis patients over the last decade: a US tertiary-center experience. Pancreatology 2017;17:32-40.

20. Koutroumpakis, E S. Management and outcomes of 400 prospectively enrolled United States patients with acute pancreatitis (AP) categorized by the revised Atlanta Classification (RAC). Am J Gastroenterol 2014;109:S78.

21. Kwong WT-Y, Ondrejková A, Vege SS. Predictors and outcomes of moderately severe acute pancreatitis - evidence to reclassify. Pancreatology 2016;16:940-5.

22. Soran A, Chelluri L, Lee KK, et al. Outcome and quality of life of patients with acute pancreatitis requiring intensive care. J Surg Res 2000;91:89-94.

23. Mutch KL, Heidal KB, Gross $\mathrm{KH}$, et al. Cost-analysis of nutrition support in patients with severe acute pancreatitis. Int $J$ Health Care Qual Assur 2011;24:540-7.

24. Talukdar R, Clemens M, Vege SS. Moderately severe acute pancreatitis: prospective validation of this new subgroup of acute pancreatitis. Pancreas 2012;41:306-9.

25. Gonzelez HJ, Sahay SJ, Samadi B, et al. Splanchnic vein thrombosis in severe acute pancreatitis: a 2-year, single-institution experience. HPB 2011;13:860-4.

26. Hall AM, Poole LAL, Renton B, et al. Prediction of invasive candidal infection in critically ill patients with severe acute pancreatitis. Critical Care 2013;17:R49.

27. Harrison DA, D'Amico G, Singer M. Case mix, outcome, and activity for admissions to UK critical care units with severe acute pancreatitis: a secondary analysis of the ICNARC case mix programme database. Critical Care 2007;11(Suppl 1):S1.

28. Patel G AR. Lessons learnt from the management of severe acute pancreatitis in the critical care unit. $A m \mathrm{~J}$ Gastroenterol 2015;110:S30.

29. Heiss P, Bruennler T, Salzberger B, et al. Severe acute pancreatitis requiring drainage therapy: findings on computed tomography as predictor of patient outcome. Pancreatology 2011;10:726-33.

30. Rasch, S S, Phillip V, Reichel S, et al. Open surgical versus minimal invasive necrosectomy of the Pancreas -A retrospective multicenter analysis of the German pancreatitis Study Group. Plos One 2016;11:e0163651

31. Wittau M, Scheele J, Gölz I, et al. Changing role of surgery in necrotizing pancreatitis: a single-center experience. Hepatogastroenterology 2010;57:1300-4.

32. Castoldi L, De Rai P, Zerbi A, et al. Long term outcome of acute pancreatitis in Italy: results of a multicentre study. Digestive and Liver Disease 2013;45:827-32.

33. Cinquepalmi L, Boni L, Dionigi G, et al. Long-term results and quality of life of patients undergoing sequential surgical treatment for severe 
acute pancreatitis complicated by infected pancreatic necrosis. Surg Infect 2006;7:s-113-s-116.

34. De Rai P, Zerbi A, Castoldi L, et al. Surgical management of acute pancreatitis in Italy: lessons from a prospective multicentre study. HPB 2010;12:597-604.

35. Gomercic C, Gelsi E, Van Gysel D, et al. Assessment of D-dimers for the early prediction of complications in acute pancreatitis. Pancreas 2016;45:980-5.

36. Pintado M-C, Trascasa M, Arenillas C, et al. New Atlanta Classification of acute pancreatitis in intensive care unit: complications and prognosis. Eur J Intern Med 2016;30:82-7.

37. Gougol A, Dugum M, Dudekula A, et al. Clinical outcomes of isolated renal failure compared to other forms of organ failure in patients with severe acute pancreatitis. World J Gastroenterol 2017;23:5431-7.

38. Koutroumpakis E, Dasyam AK, Furlan A, et al. Isolated peripancreatic necrosis in acute pancreatitis is infrequent and leads to severe clinical course only when extensive: a prospective study from a US tertiary center. J Clin Gastroenterol 2016;50:589-95.

39. Krishna SG, Hinton A, Oza V, et al. Morbid obesity is associated with adverse clinical outcomes in acute pancreatitis: a PropensityMatched study. Am J Gastroenterol 2015;110:1608-19.

40. Kulvatunyou N, Watt J, Friese RS, et al. Management of acute mild gallstone pancreatitis under acute care surgery: should patients be admitted to the surgery or medicine service? Am J Surg 2014;208:981-7.
41. Kumar A, Chari ST, Vege SS. Can the time course of systemic inflammatory response syndrome score predict future organ failure in acute pancreatitis? Pancreas 2014;43:1101-5.

42. Mounzer R, Langmead CJ, Wu BU, et al. Comparison of existing clinical scoring systems to predict persistent organ failure in patients with acute pancreatitis. Gastroenterology 2012;142:1476-82.

43. Singh VK, Gardner TB, Papachristou GI, et al. An internationa multicenter study of early intravenous fluid administration and outcome in acute pancreatitis. United European Gastroenterol J 2017;5:491-8.

44. Talukdar, R B. Validation of the revised Atlanta definitions of severity of acute pancreatitis: have all loose ends being tied? Indian $J$ Gastroenterol 2013;32:A104.

45. Talukdar R, Nechutova $\mathrm{H}$, Clemens $\mathrm{M}$, et al. Could rising bun predict the future development of infected pancreatic necrosis? Pancreatology 2013;13:355-9.

46. Meyrignac $\mathrm{O}$, Lagarde $\mathrm{S}$, Bournet $\mathrm{B}$, et al. Acute pancreatitis: extrapancreatic necrosis volume as early predictor of severity. Radiology 2015;276:119-28.

47. Pallisera A, Jorba R, Ramia J, et al. Biological markers of severity in acute pancreatitis. Cent Eur J Med 2014;9:550-5.

48. Uomo G, Pezzilli R, Gabbrielli A, et al. Diagnostic assessment and outcome of acute pancreatitis in Italy: results of a prospective multicentre study. Prolnf-AISP: Progetto informatizzato pancreatite acuta, Associazione Italiana Studio pancreas, phase II. Dig Liver Dis 2007;39:829-37. 